\title{
Introdução ao tema: podemos conjeturar como será o futuro?
}

Introduction: can we conjecture about the future?

\author{
Carmem Keidann, Flávio Shansis*
}

* Editores, Rev Psiquiatr RS.

Muito tem se debatido se os rumos da psiquiatria atual estão sendo, de fato, os mais adequados. Isso diz respeito tanto aos sistemas classificatórios contemporâneos e à aplicação de resultados de pesquisa, quanto à capacidade de estarmos, de fato, proporcionando melhores condições de vida a nossos pacientes. E maior debate ainda proporciona, a nosso ver, tentar prever para onde levarão os rumos do pensamento psiquiátrico contemporâneo. Nesse sentido, resolvemos convidar quatro colegas a conjeturar como será o futuro: afinal, qual será a psiquiatria que nos espera nos próximos 50 anos?

Ao Professor German Berrios, da Universidade de Oxford, no Reino Unido, reconhecido pensador da história da psiquiatria, perguntamos se "em psiquiatria, o conhecimento histórico pode ter capacidade preditiva”. O Dr. Berrios inicia seu texto discutindo a complexidade da questão provocadora, sugerindo que a resposta depende das definições do que entendemos por psiquiatria, história e capacidade preditiva. Chama atenção de que a evolução da psiquiatria pode ser determinada mais por fatores econômicos, sociais e políticos do que por justificativas científicas. Faz um alerta de que mesmo sua atual relação com a medicina poderia deixar de existir, se fossem descobertas outras maneiras mais "mercadológicas” de tratar a doença mental.

O Dr. Andrew Nieremberg, da Universidade de Harvard, em Boston, Estados Unidos, é um iminente pesquisador clínico na área de transtornos de humor. Ele questiona o valor de muitos ensaios clínicos atualmente realizados, onde são ocultados resultados negativos e/ou riscos de seus produtos em função de uma meta desenfreada de lucros. Alerta para o problema da generalização dos resultados desses estudos, pois há uma importante diferença entre pacientes que participam de pesquisas e os que procuram tratamento clínico. Comenta sobre o fato de a quase totalidade de fontes de financiamento de pesquisas ter origem em empresas farmacêuticas particulares e, portanto, fazem-se necessárias outras fontes de financiamento de pesquisas de diferentes origens (governamentais, ONGs, fundações). Reconhece, finalmente, a importância das pesquisas sobre efetividade dos tratamentos para promover a saúde pública e a necessidade, portanto, de serem diminuídos vieses que comprometam seus resultados.

O colega, Cláudio Eizirik, da Universidade Federal do Rio Grande do Sul, Brasil, e atual presidente da International Psychoanalitic Association (IPA), refletiu sobre a contribuição que o pensamento psicanalítico poderá exercer na psiquiatria em 50 anos. O Professor Eizirik acredita que a psicanálise seguirá possibilitando a compreensão das emoções que fazem parte da vida humana, tanto em nível do atendimento do paciente, quanto das intrincadas relações nas instituições, através de seus conceitos como transferência e contratransferência, campo analítico, intersubjetividade, mente em expansão. Ressalta o crescimento da psicoterapia de orientação analítica com benefícios que se estendem à rede pública e a serviços universitários. Segundo Eizirik, a psicanálise estará presente na formação de novos psiquiatras, instrumentando-os a compreender e tratar os transtornos psiquiátricos multideterminados. Mantém firme a expectativa de uma integração efetiva entre a psicanálise e psiquiatria no futuro.

Ao Dr. Gabbard, da Baylor College of Medicine de Houston, Estados Unidos, perguntamos se será possível integrar a psicanálise e pesquisa clínica no futuro. Ele sintetiza sua posição afirmando que a integração entre a psicanálise e a pesquisa em neurociência clínica não só é possível, como também fundamental. Alerta para o risco de sedução pelos avanços do conhecimento tecnológico. Segundo Gabbard, a psiquiatra contemporânea necessita de duas linguagens - uma mais adequada para a biologia e outra derivada da psicologia. Esse psiquiatra, já denominado há alguns anos por Gabbard como “bilíngüe”, 
manteria um modelo integrador entre mente e cérebro. Finalmente, sugere que a psiquiatria seguirá um bom rumo se, daqui a 50 anos, pudermos abarcar melhor a enorme amplitude do homem, fugindo de uma explicação puramente psicanalítica ou puramente biológica dos eventos humanos.

Prever o futuro sempre carrega um enorme potencial de vieses. Imaginar como a psiquiatria será daqui a 50 anos é um exercício puramente intelectual. Os Profs. Berrios, Nieremberg, Eizirik e Gabbard aceitaram nosso desafio e sugeriram caminhos e possibilidades para a manutenção ou mudanças que se fazem necessárias em nossa especialidade. Nas páginas seguintes, o leitor terá o prazer de desfrutar das reflexões tão bem articuladas pelos nossos convidados. É um privilégio contarmos com estas participações. 